\title{
Molecular Characterization and Serotyping of Listeria monocytogenes with a Focus on Food Safety and Disease Prevention
}

\author{
I.C. Morobe' ${ }^{1,2,4}$, C.L. Obi ${ }^{1,3}$, M.A. Nyila ${ }^{2}$, M.I. Matsheka ${ }^{4}$ and B.A. Gashe ${ }^{4}$ \\ ${ }_{1}$ Walter Sisulu University, Nelson Mandela Drive, Mthatha, Eastern Cape, \\ ${ }^{2}$ School of Agriculture and Life Sciences, Department of Life and Consumer Sciences, \\ University of South Africa, Pretoria, \\ ${ }^{3}$ Division of Academic Affairs and Research, Walter Sisulu University, Eastern Cape, \\ ${ }^{4}$ Department of Biological Sciences, University of Botswana, Gaborone, \\ 1,2,3 South Africa \\ ${ }^{4}$ Botswana
}

\section{Introduction}

Listeria monocytogenes is a gram-positive, non-spore forming, facultative bacterium that is now an established food-borne pathogen known for causing the disease listeriosis in humans. Apart from displaying typical symptoms associated with gastrointestinal infections, listeriosis is also characterized by flu-like symptoms. The incidence of listeriosis is low in the general population, but what is significant is the very high fatality rate which can range from 20 to $30 \%$ in immune-compromised people (Mead et al., 2006). In a report by Mead et al., (2006) approximately 2500 cases of Listeriosis are recorded annually in the United States, resulting in 500 deaths. The primary mode of infection is through the ingestion of contaminated food. Therefore, food serves as an important medium in the transmission of infection and to date still plays a critical role in the propagation and perpetuation of cases of listeriosis the world over.

The ubiquitous nature of L. monocytogenes in the environment poses a challenge in reducing cases of listeriosis. The food industry is incapacitated in producing food free of this pathogen. Its wide distribution increases the chances of cross-contamination between appliances or several products during processing. Listeria also has the ability to colonize surfaces, forming biofilms that remain attached to equipment used in food production (Wong et al., 1998). The organism ability to grow at low water activity, low $\mathrm{pH}$ (Buchanan et al., 2000) as well as refrigerated vacuum packed food products (Duffy et al., 1994) makes it difficult to eliminate from retail food products. L. monocytogenes is also problematic due to its resistance to multiple antibiotics, which makes it difficult to treat (Charpentier et al., 1995).

Listeria Monocytogenes is divided into at least 12 serotypes $(1 / 2 \mathrm{a}, 1 / 2 \mathrm{~b}, 1 / 2 \mathrm{c}, 3 \mathrm{a}, 3 \mathrm{~b}, 3 \mathrm{c}, 4 \mathrm{a}$, $4 \mathrm{~b}, 4 \mathrm{c}, 4 \mathrm{~d}, 4 \mathrm{e}$, and 7). The virulence of Listeria monocytogenes seems to be serotype dependent with serotypes $1 / 2 a, 1 / 2 c, 1 / 2 b$ and $4 b$ being involved in $98 \%$ of documented human 
listeriosis cases. The 4a and 4c serotypes of lineage are rarely associated with outbreaks of disease despite frequent isolation from a variety of food and environmental samples (Wiedmann et al., 1997). Therefore, serotyping can provide useful information on the potential risk posed by Listeria monocytogenes isolates from various sources.

The conventional serotyping slide agglutination technique has been uses with great success in diagnostic and epidemiological investigations but is not routinely used because of the cost factor associated with the requirement of purchasing the whole spectrum of type specific antisera. Lack of standardization of reagents is known to hinder reproducibility of the technique. An enzyme-linked immunosorbent assay (ELISA) with the prospect of rapid serotyping of L. monocytogenes has been developed, but lack of concordance between the ELISA and agglutination results have been reported (Borucki et al., 2003).This limitation has spurred a quest for alternative based typing techniques with universal application. Consequently L. monocytogenes PCR based serotyping methods have been described (Borucki et al., 2003; Doumith et al., 2004; Chen and Knabel, 2007) and chart a way into the establishment of a user friendly DNA based serotyping system. L. monocytogenes can now be further classified into three evolutionary lineages. Lineage I encompasses serotypes $1 / 2 b$, $3 \mathrm{~b}, 4 \mathrm{~b}, 4 \mathrm{~d}$ and 4 , lineage II includes serotypes $1 / 2 \mathrm{a}, 1 / 2 \mathrm{c}, 3 \mathrm{a}$, and $3 \mathrm{c}$; and lineage III comprises serotypes $4 \mathrm{a}, 4 \mathrm{c}$ as well as $4 \mathrm{~b}$.

While the PCR based serotyping methods play an important role in screening of subgroups of epidemiological importance, they need to be used in conjunction with sub-typing methods with higher discriminatory power in order to effectively track outbreak strains. Automated ribotyping of Listeria monocytogenes is an alternative DNA based typing technique of favor that has been used with great success in several investigations. However, this method has a prohibitive cost element, in that specialized equipment has to be purchased to analyze the results. PCR based typing methods remain an attractive cost effective option in sub-typing of bacterial isolates and have an added advantage of being rapid. REP-typing is a highly discriminatory typing technique has been used with success in epidemiologically surveillance of pathogenic bacteria of importance, including Listeria (Jersek et al., 1998; Wojciech et al., 2004).

Even though a past study by Manani et al., (2006) reported the occurrence of Listeria monocytogenes in frozen vegetables in this country, there is little data on the occurrence of this pathogen in foods available to consumers in Botswana. The REP-typing method described by Jersek et al, (1998) together with the modified PCR serotyping method initially described by Borucki et al., (2003), were used to determine the of presence of Listeria serotypes of clinical significance in various retail food products in Botswana. These methods have predominantly been used in isolates from Europe and North America (Chen and Knabel, 2007) and this study provided the opportunity to assess the robustness and appropriateness of the genetic markers underpinning these DNA based typing techniques in characterizing isolates from a geographically distinct region.

\section{Literature review}

\subsection{Listeria disease}

Listeria includes 6 different species, L. monocytogenes, L. ivanovii sub-species, ivanovii, L. innocua, L. welshimeri, L. seegligeri and L. grayi. Both L. monocytogenes L. innocua and ivanovii 
L. are pathogenic, but only L. monocytogenes is associated with humans and animal illness (Rodriguez-Lazaro et al., 2004). All these species are psychotrophic and widely spread in the environment. L. innocua is a major contaminant of vegetable surfaces and equipment or machinery (Aguado et al., 2004).

Listeria monocytogenes appears to be a normal resident of the intestinal tract in humans. Studies carried out by examination of faecal samples, have found out that approximately 5 to $10 \%$ of the general population are carriers of L. monocytogenes. This observation is thought to partially explain why antibodies to Listeria species are common in healthy individuals. Thus, because of the high rate of clinically healthy carriers, the presence of $L$. monocytogenes in faeces is not necessarily an indication of an infection (Farber et al., 1991). Listeriosis is clinically defined when the organism is isolated from blood, cerebrospinal fluid and even placenta and foetus in cases of abortion. In a study of the duration of faecal excretion, shedding patterns were found to be erratic among different individuals with some carriers found to shed the organism for long periods. Among animals the carrier rate is generally considered to be 1 to $5 \%$, although recent studies involving newer methods for isolating Listeria species have indicated much higher carriage rates (Farber et al., 1991).

Ingestion of food contaminated with L. monocytogenes can result in symptoms characteristic of listeriosis. Studies have shown that the number of Listeria monocytogenes cells can rise following refrigeration from fewer than 100 cells per gram, and this is the dose that is generally accepted for healthy people (Huss et al., 2000; Buchanan et al., 2000). Individuals who are particularly susceptible to this condition are immune-compromised individual (as in HIV/AIDS infection), pregnant women, persons with low stomach acidity, newborn babies, cancer patients, alcoholics, drug abusers, patients with corticosteroid therapy and the elderly (McLauchlin et al., 2004; Rodriguez - Lazaro et al., 2004). Most healthy individuals experience flu-like symptoms. The manifestation of listeriosis includes septicemia, meningitis (meningoencephalitis), encephalitis and intrauterine or cervical infections in pregnant women. According to Mead and his colleagues (1999), Infection acquired in early pregnancy may lead to abortion, still birth or premature delivery. When listeriosis is acquired late in pregnancy it can be transmitted transplacentally and lead to neonatal listeriosis. The onset of the aforementioned disorders is usually preceded by influenza-like symptoms including persistent fever followed by nausea, vomiting and diarrhea, particularly in patients who use antacid or cimetidine. The onset time to serious forms of listeriosis ranges from a few days to 3 weeks, while the onset time to gastrointestinal symptoms is greater than 12 hours ( $>12$ hours).The severe form of the disease has a high fatality rate of $30 \%$.

\subsection{Determinants of Listeria virulence}

Listeria monocytogenes produces an exotoxin listeriolysin (LLO) which is major virulence factor and its secretion is essential for promoting the intracellular growth and T- cell recognition of the organism (Farber et al., 1991). The hemolysin of L. monocytogenes is recognized as a key agent in human neutrophil activation. The stimulation of these phagocytes, however, requires additional listerial virulence factors of which PIcA may play a prominent role (Karunasagar et al., 1993). The presence of the listeriolysin gene is restricted to the species L. monocytogenes. Beside the characterized Listeriolysin encoded by the hly gene, L. monocytogenes also produces two other hemolysins; phosphatidylinositol-specific 
phospholipase C (Pl-PLC) and phosphatidylcholine-specific phospholipase C (PC-PLC). Unlike the LLO which lyses host cells by pore formation, these virulence factors act by disrupting the membrane lipids. The bacterium also produces zinc $(2+)$ dependent protease, which acts like an exotoxin.

There are six Listeria monocytogenes virulent genes, namely; $\operatorname{prf} A, \operatorname{pcl} A, h l y A, m p l$, act $A$, and $p l c B$ located together in one virulence gene cluster between the house keeping gene $i d h$ and prs. The actA gene product is a surface protein required for intercellular movement and cell to cell spread through bacterially induced actin polymerization. The virulence of $L$. monocytogenes is multi-factorial. Other factors affecting the pathogenicity of L. monocytogenes are, iron compounds, catalase and superoxide dismutase, and surface components. The virulence of the organism may be affected by its growth temperature. Growth of $L$ .monocytogenes at a reduced temperature $\left(4^{\circ} \mathrm{C}\right)$ increases its virulence intravenously. This phenomenon may affect the virulence of the organism in refrigerated foods.

\subsection{Treatment}

When infection occurs during pregnancy, antibiotics given promptly to the pregnant women can often prevent infection of the fetus or new born. In general, isolates of $L$. monocytogenes, as well as strains of other Listeria species, are susceptible to a wide range of antibiotics except tetracycline, erythromycin, streptomycin, cephalosporins, and fosfomycin (Charpentier et al., 1999). The treatment of choice for listeriosis remains the administration of ampicillin, penicillin $\mathrm{G}$ combined with an aminoglycoside and gentamycin. The association of trimethoprim with sulphonamide, such as sulfamethaxazole in co-trimoxazole, is a second choice therapy (Charpentier et al., 1999). The most active agent in the combination is trimethoprim, which is synergized by sulfamethaxazole. Most isolates from clinical as well foodborne and environmental sources are susceptible to the antibiotics active against gram positive bacteria (Yucel et al., 2005).

\subsection{Epidemiology and occurrence of Listeria}

The incidence of listeriosis appears to be on the increase worldwide with a significant number of cases, especially in Europe. The annual endemic disease rate varies from 2 to 15 cases per million populations, with published rates varying from 1.6 to a high rate of 14.7 in France for 1986. Listeria has been isolated sporadically from wide variety of sources and listeriosis outbreaks that have occurred in the past have highlighted contaminated food as the main source of transmission. A wide range of foods such as salads, seafood's, meat, and dairy have been implicated in listeriosis (Huss et al., 2000). Usually the presence of Listeria species in food is thought to be an indicator of poor hygiene (Manani et al., 2006). A variety of ready- to-eat food products, such as frozen or raw vegetables, milk and milk products, meat and meat products and seafood support the growth of Listeria monocytogenes. These foods are considered of high risk due to the ability of listeria to grow and survive in them (Kunene et al., 1999). However, there are other products, traditionally considered of low risk, which have recently been linked to listeriosis transmission, such as the large listeriosis outbreak reported in Italy due to the consumption of corn. Though no fatalities occurred, more than 1500 people were affected (Aguado et al., 2004). There is no doubt that the susceptible population is increasing, as there is a steady increase in numbers and types of foods in which L. monocytogenes is isolated. 
In Africa the incidence of listeriosis have also been reported in countries like Zambia where 85 cases of meningitis due to Listeria were reported (Chintu et al., 1975). In Togo, 8 out of 342 healthy slaughter animals were positive for L. monocytogenes (serovars $1 / 2 \mathrm{a}$ and $4 \mathrm{~b}$ ) isolated from the intestinal lymph nodes (Hohne et al., 1975). In Northern Nigeria $27 \%$ mortality due to L. monocytogenes (serovar; 4) was reported (Onyemelukwe et al., 1983). Listeria organisms are documented to be zoonotic with one of the sources of infection being the domestic fowl. $L$. monocytogenes can be found on poultry carcasses and in poultry processing plants. The prevalence of pathogens in chickens in many countries is well documented but their presence in South African poultry products has not been extensively reported on. Two studies investigating contamination of food available from street vendors in Johannesburg have been documented (Mosupye and Von Holly 1999; 2000). The carriage of Listeria monocytogenes and other Listeria in indigenous birds has not been documented in Kenya (Njagi et al., 2004).

\subsection{Antimicrobial resistance in L. monocytogenes}

Listeria monocytogenes, as well as other Listeria spp., are usually susceptible to a wide range of antibiotics (Charpentier et al., 1995). However, evolution of bacterial resistance towards antibiotics has been accelerated considerably by the selective pressure exerted by overprescription of drugs in clinical settings and their heavy use as promoters in animals husbandry (Charpentier et al., 1995).Therefore, it was not unexpected when the first multiresistant strain of L. monocytogenes was isolated in France in 1988 (Poyart-Salmeron et al., 1990) and since then multi-resistant $L$ monocytogenes strains have been recovered from food, the environment and sporadic cases of human listeriosis (Charpentier et al., 1995). Antibiotics to which some L. monocytogenes strains are resistant to include tetracycline, gentamicin, penicillin, ampicillin, streptomycin, erythromycin, kanamycin, sulfonamide, trimethoprim, and rifampicin (Charpentier and Courvalin, 1999).

Tetracycline resistance has been the most frequently observed resistance phenotype among L. monocytogenes isolates (Charpentier et al., 1995; Charpentier and Courvalin, 1999). Six classes of tetracycline-resistance genes; tet $(\mathrm{K}), \operatorname{tet}(\mathrm{L}), \operatorname{tet}(\mathrm{M}), \operatorname{tet}(\mathrm{O}), \operatorname{tet}(\mathrm{P})$, and $\operatorname{tet}(\mathrm{S})$ have been described in Gram positive bacteria (Charpentier et al., 1995). However, only tet(L) and tet(S) have been identified in L. monocytogenes (Poyart-Salmeron et al., 1992; Charpentier and Courvalin, 1999). Tet(M) and tet(S) confer resistance by ribosomal protection, whereas the tet $(\mathrm{L})$ gene codes for a protein which promotes active efflux of tetracycline from the bacteria. Transfer of resistance between L. monocytogenes can occur in the gastrointestinal tract of domestic animals where both species live and where sub-inhibitory levels of tetracycline may be expected. In fact, tetracyclines are second most commonly used antibiotics worldwide. They are used extensively in animal foodstuffs, especially for poultry, and it is noteworthy that tetracycline resistance was the single most common resistance marker in food-borne L. monocytogenes isolated from chicken and turkey (Chopra et al., 2001). Antibiotic resistance in L. monocytogenes is reaching an era where virtually all antibiotics will be rendered ineffective because of various mechanisms employed by $L$ monocytogenes to counteract the therapeutic agents.

\subsection{Isolation and detection of L. monocytogenes}

The Genus Listeria includes 6 different species but only L. monocytogenes and L. ivanovii are known to be pathogenic. However, only $L$.monocytogenes is associated with humans and 
animal illness (Rodriguez-Lazaro et al., 2004).In the past strains were classified to species level using morphological characteristics and biochemical tests (suspect colonies, motility, catalase, hemolysins, CAMP and API Listeria identification system). Significant efforts have been dedicated to the development of enrichment media and protocols for L. monocytogenes isolation. Ideal enrichment media would facilitate recovery of injured Listeria cells and enrichment of Listeria species (L. monocytogenes) over competing microflora. In traditional culture-based assays, it becomes very difficult to detect L. monocytogenes at any level when it is greatly outnumbered by other Listeria species, such as L. innocua, which is in most cases present together with L. monocytogenes (Bille et al., 1992). Specific-specific identification with biochemical standard methods, which include sugar fermentation or the CAMP test, is laborious and time consuming and can require 1 to 2 weeks for species identification. Moreover differentiation between species and strains is not always reached (Aguado et al., 2003). A diagnostic scheme for the same day identification of food borne cells of $L$. monocytogenes has been proposed. Large representative colonies that emerge in 40 hours at $30^{\circ} \mathrm{C}$ are used as heavy inoculum on agar plates for the rapid determination of hemolytic activity and acidification of rhamnose and xylose. Additional tests consisting of cell phasecontrast microscopy, motility testing, the catalase production test and the $\mathrm{KOH}$ viscosity test in place of Gram staining have been employed in the rapid identification of L. monocytogenes (Borucki et al., 2003).

The rapid identification of L. monocytogenes is important so that the appropriate antibiotic therapy can be initiated. Currently molecular methods that enable the identification of Listeria to the species level include; Random Amplified Polymorphic DNA Polymorphism, to discriminate Listeria monocytogenes from Listeria innocua (in the 16S rRNA genes), Polymerase Chain Reaction (PCR), real time PCR, Ligase Chain Reaction (LCR) for the detection of Listeria monocytogenes and Pulse-field fingerprinting of listeria, for detection of genomic divisions for L. monocytogenes and their correlation with serovars, and restriction endonuclease analysis (REA), have been employed to directly characterize the microorganism without the need for isolation (Wouters et al., 1999). These new molecular methods may also improve the ability to diagnose pregnancy -associated disease and permit the rapid detection and control of L. monocytogenes in the food supply (Wiedmann et al., 1993).

The Listeriolysin genes have also been used identification. DNA hybridization studies have shown that listeriolysin genes are found in Listeria species, such as L. monocytogenes, $L$. ivanovii, L. seeligeri. In the analysis of genomic DNA of Listeria by southern hybridization with $h l y A$ probes all strains were isolated and digested with the restriction endonuclease HindIII. The $0.8-\mathrm{kb}$ BamHI probe that was made up entirely of sequences upstream of the listeriolysin gene was found to hybridize to L. monocytogenes strains irrespective of serotype, as well as to the L. seeligeri and L. ivanovii strains (Borucki et al., 2003). Other methods that can be employed to detect listerolysin are; hemolysin assays and polyacrylamide gel electrophoresis, imuno-magnetic beads for listeria and Listeria exotoxin detection kits (Borucki et al., 2003). Immunoblotting performed with affinity-purified antibody to literiolysin allowed the detection of this protein in supernatants of all three species. In this immunological assay two recombinants, (pLM47 and pLM48) were found to produce a polypeptide of $60 \mathrm{KDa}$ which cross-reacted with the antisera to produce a hemolytic phenotype on blood agar plates (Leimeister- Wachter et al., 1992). 


\subsection{Typing of L. monocytogenes.}

L. monocytogenes strains are serotyped according to variation in the somatic $(\mathrm{O})$ and flagellar (H) antigens (Seeliger and Hohne, 1979). Thirteen L. monocytogenes serotypes (serovars) have been characterized in this species by using specific and standardized sera (Seeliger \& Langer, 1979). Serovar identification by serological tests has remained popular. However, numerous molecular biology methods such as multiplex PCR (Borucki et al., 2003; Doumith et al., 2004; Chen and Knabel) have come to the fore in the characterization of $L$. monocytogenes serotypes. Three genetic lineages (I, II, III) for L. monocytogenes have been identified using these various molecular subtyping techniques. Epidemic clone I contains serotypes $1 / 2 b, 3 b, 3 c$, and $4 b$, lineage II contained serotypes $1 / 2 a, 1 / 2 c$, and $3 a$ and lineage III contained serotypes $4 \mathrm{a}$ and $4 \mathrm{c}$ (Chen and Knabel, 2007). Although most clinical isolates belong to serovars $1 / 2 a, 1 / 2 b$, and $4 b$, the majority of strains which have caused large outbreaks are serovars 1/2a and 1/2b (Kathariou, 2000); Jacquet et al., 2002; Zhang and Knabel, 2005). Interestingly, although serotype $1 / 2 \mathrm{a}$ is the most frequently isolated from food, serotype $4 \mathrm{~b}$ causes the majority of human epidemics (Zhang and Nabel., 2005). This suggests that serovar $4 \mathrm{~b}$ may pose unique virulence properties. However, geographical differences in the global distribution of serotypes apparently exist.

Phage typing has proven to be a valuable epidemiological tool in investigations of many infectious diseases. Since the initial discovery phages specific for listeria species in 1945, several groups have assessed the usefulness of phage typing L. monocytogenes. Phages derived from both environment sources and lysogenic strains have been found. In isozyme typing, bacteria are differentiated by the variation in the electrophoretic mobility of any of a large number of metabolic enzymes. This technique is useful in either confirming or eliminating a common source as the cause of an outbreak of food-borne listeriosis (Farber et al., 1991).

DNA fingerprinting using restriction enzyme analysis (REA) has recently been used to characterize strains of L. monocytogenes causing outbreaks of listeriosis associated with Mexican-style soft cheese in Los Angeles, as well as the Nova Scotia and Switzerland outbreaks (Aguado et al., 2004). Plasmid typing has also been used in conjunction with DNA fingerprint to confirm a case of cross-infection with L. monocytogenes. However, this technique is of less importance since $L$.monocytogenes does not appear to carry plasmid. On the other hand L. innocua carry plasmids ranging in size from 3 to $55 \mathrm{MDa}$ (Aguado et al., 2004). Monocine typing has recently been evaluated as a typing tool for L. monocytogenes. Although this technique is potentially promising as an epidemiological tool, only 59 and 56 $\%$ of serovars $1 / 2 \mathrm{a}$ and $4 \mathrm{~b}$ were found to be producers of monocines. In one instance a pair of L. monocytogenes strains isolated from a mother and a newborn, which could not be phage typed, but proved to be identical by monocine typing (Baloga et al., 2006).

\section{Materials and methods}

\subsection{Sampling}

Samples were obtained randomly from selected supermarkets and street vendors in 5 Geographical areas of Gaborone Samples collected were; raw vegetables (cabbage) and salads, raw milk, cheese and meat (biltong). In this study 250 -300 samples per product were obtained. Samples were put in separate properly labeled sterile specimen bags and put into 
a cooler box containing ice packs. Gloves were worn to avoid cross- contamination between samples from different supermarkets and street vendors. Samples were transferred into properly labeled stomacher bags and then homogenized with the Stomacher (Seward 400, Tekmar, and Cincinnati Ohio, USA) set at medium speed. Listeria monocytogenes positive control (ATCC 19115) was purchased from South African Bureau of Standards (SABS).

\subsection{Enrichment, culturing, morphological observation and biochemical identification}

The homogenized samples were enriched by putting $25 \mathrm{~g}$ of the sample into $225 \mathrm{ml}$ enrichment broth (Mast Diagnostics DM257) and incubated at $30^{\circ} \mathrm{C}$ for 48 hours on Innova 4000 Newbrunswick Scientific incubator shaker. A loop full of culture was subcultured after 48 hours onto Listeria Selective Agar (Oxoid M009, Basingstoke, UK) plates and then incubated at $37^{\circ} \mathrm{C}$ for 24 hours. Modified Listeria Selective Enrichment Supplement (SR206E, Oxoid, Basingstoke, and Hampshire, England) was added to Listeria Agar Base and dark brown colonies with black zones were subcultured on nutrient agar (Oxoid CM001) plates. A Gram stain was done on suspected colonies from a culture medium (Nutrient Agar). Gram positive short rods colonies picked were subcultured onto Tryptic Soya Agar (Merck, Darmstadt, Germany) slants. After 24 hour incubation, the slants were kept at $4^{\circ} \mathrm{C}$. Other broth cultures were stored in $80 \%$ Tryptic Soya Broth and $20 \%$ Glycerol (i.e., $750 \mu 1$ Tryptose broth plus $250 \mu \mathrm{l}$ of $20 \%$ Glycerol) were put into a $2 \mathrm{ml}$ vial and kept at $-82^{\circ} \mathrm{C}$ for subsequent steps.

\subsubsection{Biochemical testing}

A catalase test was performed to separate the listeria (catalase positive) from listeria (catalase negative). Picking a colony with sterile loop on a slide containing $3 \%$ hydrogen peroxide does this. The evolution of gas bubbles (oxygen) indicates a positive test. Seroagglutination was carried out by a slide agglutination technique using commercially prepared Listeria spp. antisera (Oxoid Listeria test kit DR1126A, Basingstoke, New Hampshire, England). Agglutination patterns were linked to Listeria spp. following manufacturer's instructions. Isolates that were positive in the serology test were subjected to the API Listeria test (BioMerieux, Paris, France). This is the confirmatory test for the organism and it differentiates L. monocytogenes from other Listeria species.

\subsection{Serotype identification by PCR}

\subsubsection{DNA extraction}

L. monocytogenes strains were stored long term in tryptic soy broth (Merck, Darmstadt, Germany) with $20 \%$ glycerol at $-82^{\circ} \mathrm{C}$. Strains were then recovered by inoculating into tryptose soy broth and were grown overnight at $37^{\circ} \mathrm{C}$. Cells were harvested on a bench top centrifuge and genomic DNA extracted using Guanidium Thiocyanate chromosomal technique (Pitcher et al., 1989). 500 $\mu$ l of guanidium thiocyanate solution (60g Guanidium thiocyanate, 20ml 0.5M EDTA pH8,20ml deionized water and $5 \mathrm{ml}$ of $10 \%$ (w/v) N-LaurylSarcosine Sodium salt, made up to $100 \mathrm{ml}$ with deionized water) was added and briefly mixed to lyse the cells. $250 \mu \mathrm{l}$ ice-cold $7.5 \mathrm{M}$ ammonium acetate was added, mixed and left on ice for 10 minutes. 500 $\mu$ l Chloroform/ Isopropanol (24:1) was added, mixed and span at $1200 \mathrm{~g}$ for 10 minutes. $600 \mu \mathrm{l}$ supernatant was transferred to clean Eppendorf tubes and $400 \mu \mathrm{l}$ 
ice -cold isopropanol was added, mixed by gentle inversion of the Eppendorf tube and span at $6500 \mathrm{~g}$ for 20 seconds to collect DNA. The pellet was washed three times with $200 \mu \mathrm{l}$ of icecold $70 \%$ alcohol, span at $6500 \mathrm{~g}$ for 2 minutes to remove excess Guanidium thiocyanate. The pellet was then air dried at $4{ }^{\circ} \mathrm{C}$ for 7 minutes and resuspened in $30 \mu \mathrm{l}$ of TE buffer and kept at $4^{\circ} \mathrm{C}$ for subsequent steps.

\subsubsection{PCR amplification}

Amplification of serotype specific hly gene product of $214 \mathrm{bp}$ and the Serogroup identification by multiplex PCR using primer pairs D1 and D2. PCR using reverse and forward primers (D1-Forwad; 5' CGATATTTTATCTACTTTGTC 3'; D1-Reverse; 5' TTGCTCCAAAGCAGGGCAT 3' and D2-Forward; 5' GCGGAGAAAGCTATCGCA 3'; D2Reverse; 5' TTGTTCAAACATAGGGCTA 3') as described by Borucki and Call (2003). Reaction mixtures was made up to $50 \mu \mathrm{l}$ using the high pure PCR template kit (Fermentas) and Roche PCR core kit reagent according to manufacturer's instructions. Each reaction consisted of $50 \mathrm{pmol}$ of each primer and 50ng of DNA template with 2.5 units of Tag polymerase.

Amplification was carried out using Applied Biosystems GeneAmp 2400 thermocycler. PCR cycling conditions were as follows; $95^{\circ} \mathrm{C}$ for 3 minutes followed by 25 cycles (with D1 and $\mathrm{D} 2$ primers) $72^{\circ} \mathrm{C}$ for 1 minute followed by a final step of $72^{\circ} \mathrm{C}$ for 10 minutes after cycling was completed. The product size was resolved using electrophoresis through $1.8 \%$ agarose gels containing ethidium bromide and visualized on a UV transilluminator. During this experiment laboratory control strain of L. monocytogenes were used as a positive control, included in each group of samples undergoing analysis.

The strains that tested positive with D1 primers were further subjected to PCR using GLT primers ( GLT-Forward 5'- AAA GTG AGT TCT TAC GAG ATT T-3' and GLT-Reverse 5'AAT TAG GAA ATC GAC CTT CT-3'). The PCR reaction conditions were as mentioned above but with a different PCR cycling protocol. Initial denaturation was carried out at $95^{\circ} \mathrm{C}$ for 5 minutes followed by 25 cycles of $45^{\circ} \mathrm{C}$ for 30 seconds and $72^{\circ} \mathrm{C}$ for 1 minute, followed by a final step of $72^{\circ} \mathrm{C}$ for 10 minutes after cycling was completed. PCR products were determined using electrophoresis through $1.8 \%$ agarose gel containing ethedium bromide and visualized on a UV transilluminator.

\subsubsection{Lineage group classification by MAMA - PCR}

MAMA primers were used to test strains that tested negative with GLT primers. The high pure PCR template kit (Fermentas) was used according to the manufacturer's instructions. Reaction mixtures contained primers (LM4-Forward (5'- CAG TTG CAA GCG CTTGGAGT$3^{\prime}$ ) and LMB-Reverse (5'- GTA AGT CTC CGA GGT TGC AA-3') at a concentration of 50pmoles. MAMA-PCR amplification conditions were as follows; 10 minutes initial denaturation step, followed by 40 cycles of 0.5 minutes at $95^{\circ} \mathrm{C}, 1$ minute at $55^{\circ} \mathrm{C}$ and 1 minute at $72^{\circ} \mathrm{C}$, with a final extension step for 10 minutes at $72^{\circ} \mathrm{C}$. Amplification product was electrophoresed on a $1.5 \%$ agarose gel containing $0.4 \mu \mathrm{g} / \mathrm{ml}$ ethidium bromide at 60 volts for 90 minutes and visualized on a UV transilluminator.

The strains that tested positive with MAMA primers were subjected to PCR using ORF2110 primers (Forward: 5' - AGTGGACAATTGATTGGTGAA-3' and Reverse: 5'- 
CATCCATCCCTTACTTTGGAC-3') as described by Doumith et al. (2004) at a concentration of 50pmoles.ORF2110 - PCR amplification conditions were as follows; initial denaturation step at $94^{\circ} \mathrm{C}$ for 3 minutes followed by 35 cycles of $94^{\circ} \mathrm{C}$ for 0.40 minutes, $53^{\circ} \mathrm{C}$ for 1 minute and $72^{\circ} \mathrm{C}$ for 1 minute and one final cycle of $72^{\circ} \mathrm{C}$ for 7 minutes. Amplification product was electrophoresed on a $1.5 \%$ agarose gel containing $0.4 \mu \mathrm{g} / \mathrm{ml}$ ethidium bromide at 60 volts for 90 minutes and visualized on a UV transilluminator.

\subsection{Typing by repetitive element sequence - based PCR}

Amplification of REP-PCR products was done using REP IR - I 5' - IIIICGICGICATCIGGC$3^{\prime}$ and REP 2-1 5'-ICGICTTATCIGGCCTAC-3' primer pairs as described by Jersek et al.,

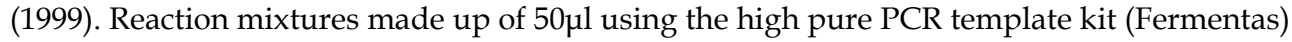
and Roche PCR core kit reagents were used according to the manufacturer's instructions. Each reaction consisted of 50pmol of each primer and 50ng of DNA template with 2.5 units of Tag polymerase. REP - PCR cycling conditions were as follows; An initial denaturation at $95^{\circ} \mathrm{C}$ for 3 minutes followed by 30 cycles of $90^{\circ} \mathrm{C}$ for 30 seconds at $40^{\circ} \mathrm{C}$ for 1 minute, at $72^{\circ} \mathrm{C}$ for 1 minute and final cycle at $72^{\circ} \mathrm{C}$ for 8 minutes. The REP-PCR gene products were resolved into finger printing patterns on a 1.5\% agarose gel (Roche) at 60Volts for 1 hour. Gel images captured on the Syngene Gene Genius BioImaging System (Cambridge, UK). Fingerprint patterns were considered different if there was a presence or absence of a band at a particular molecular weight. Variations in the brightness of the band, was not considered to constitute a difference. The gel images were subjected to cluster analysis using GelCompar software (Applied Maths, Kortrijk, Belgium). The similarity was performed using the Dice coefficient. A band matching tolerance of $1.0 \%$ was chosen.

\section{Results}

\subsection{Isolation and identification of $L$. monocytogenes}

From the five various food products (Cheese, raw milk, Biltong, frozen cabbage and Coleslaw salad), 57 isolates of L. monocytogenes were recovered from all food types except biltong. These isolates were identified as Listeria by using the seroagglutination test and positively identifies as L. monocytogenes using phenotypic and biochemical testing.

\subsection{Serogroup identification by Polymerase Chain Reaction (PCR)}

Serogroup identification by PCR was performed on all the 57 confirmed L. monocytogenes isolates. Using primer pairs D1 a PCR product of 214bp was for the entire strains analyzed. The PCR product of this size suggests serotypes belonging to phylogenetic lineage of division I and III, which comprise serogroups $4 a, 1 / 2 b, 3 b, 4 b, 4 c, 4 d$ and $4 e$. No PCR product was obtained for all 57 isolates using The D2 Lineage II specific primers.

To differentiate $1 / 2 b$ and $3 b$ serotypes from the rest of the members in division $I$, the strains that tested positive with D1 primers were subjected to PCR using GLT primers. Only 6 $(10.52 \%)$ strains gave the expected PCR product size of $483 \mathrm{~b}$. In one specific case the primers gave an amplicon bigger than the expected PCR product (Fig 2 lane 4).

Strains that did not give any product (amplicon) or the expected PCR product size with GLT primers were assumed to belong to either division I or division III. To differentiate the 


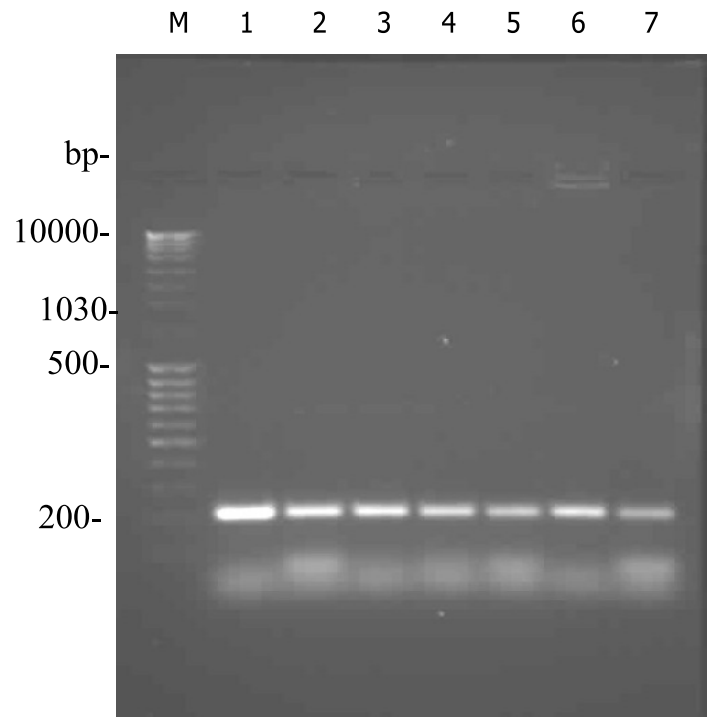

Fig. 1. Genomic DNA from Listeria monocytogenes strains subjected to multiplex PCR with primer pairs for D1 and D2. Showing the 214bp PCR product (lanes 1-7). Lane M, MassRuler TM SM0403 (Fermentas).

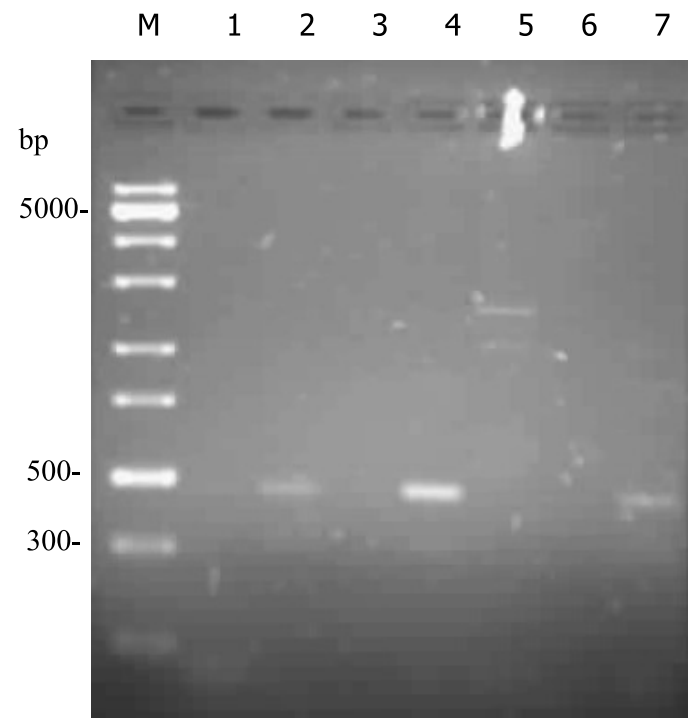

Fig. 2. Genomic DNA from Listeria monocytogenes strains subjected to PCR with GLT primers. Lane 2, 3 and 7 (ATCC 19115 strain) depicting isolates with the expected 483bp PCR product. Lane M, ZipRuler TM SM1378 (Fermentas).

isolates belonging to serogroup $4 \mathrm{~b}, 4 \mathrm{~d}$ and $4 \mathrm{e}$, the isolates which did not give a PCR product with GLT primers were again subjected to PCR with primers specific to ORF2110. Seventeen 
of the 57 isolates gave a $597 \mathrm{bp}$ amplicon when the PCR product was resolve on a $1.5 \%$ agarose gel. In certain instances unspecific priming was evident (Fig 3 lanes 4, 5 and 6).

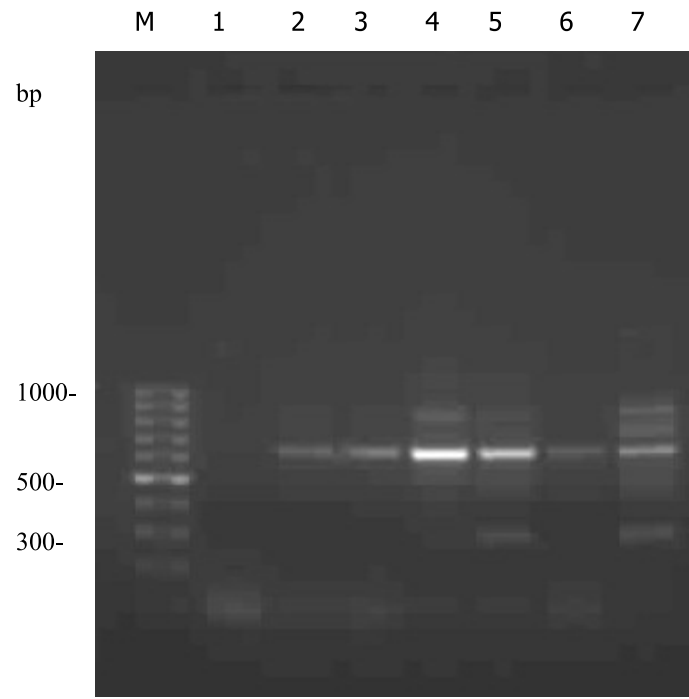

Fig. 3. Genomic DNA from Listeria monocytogenes strains subjected to PCR with primers specific to ORF 2110. Lane 2, 3, 4, 56 and 7(ATCC19115 strain) depicting isolates with the expected 596bp PCR product. Lane M, GeneRuler TM SM1148 (Fermentas).

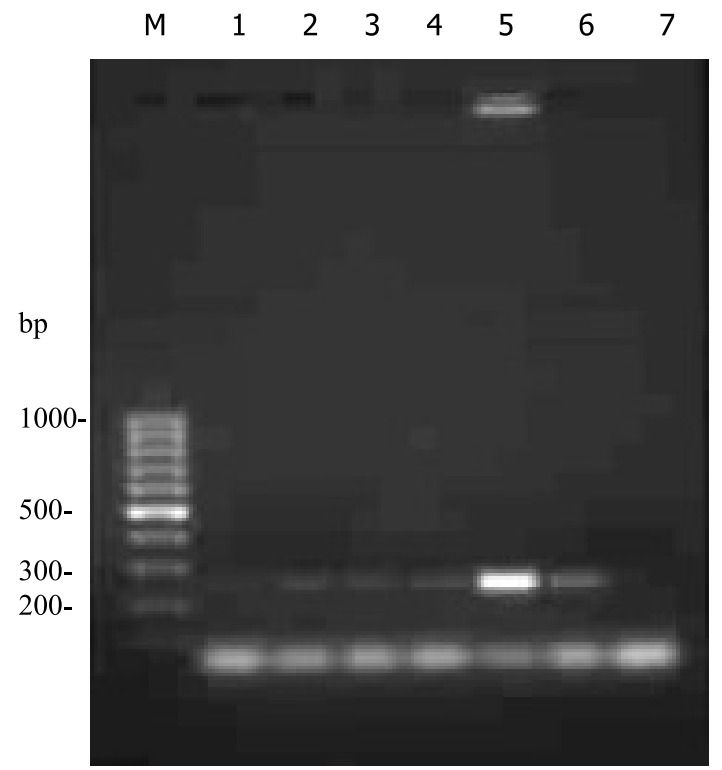

Fig. 4. Genomic DNA from Listeria monocytogenes strains subjected to PCR with MAMA-C primers. Lanes 2 to 6 show the expected 268bp PCR product. Lane M, GeneRulerTM SM 1148. 
Furthermore the isolates that were GLT negative were subjected to PCR using MAMA-C primers to identify isolates belonging to division III. From the 51 isolates that were negative for GLT primers, 45 isolates gave a $268 \mathrm{bp}$ product with MAMA-C specific primers, indicating suggesting that they belonged to Division III. Included in the 45 positive isolates that were positive for PCR with MAMA-primers were the 17 isolates that had proved of positive for ORF2110 specific primers. The rhamnose fermentation test was positive for all 45 isolates suggesting that they belonged to division III.

Serogroup identification using PCR found that most isolates (49\%) belonged to serogroups 4a and 4c. These isolates were found mostly in cabbage and salads. This was followed by isolates in serogroups $4 \mathrm{~b}, 4 \mathrm{~d}$ and $4 \mathrm{e}$ which comprised $30 \%$ of the isolates. Isolates within this group appeared in all food types except salads and cheese. Isolates with serogroups $1 / 2 b$ and $3 \mathrm{~b}$ were rare with four isolates appearing in salads and one isolate being picked up in cheese and milk respectively. Isolates belonging to division II were not detected at all because no isolates were positive for PCR using D2 specific primers. Four isolates in salads (S10, S31, S200, S258) and two (V208, V225) in cabbage were found to belong to division I, but could not be characterized further into serogroups because they proved to be negative for PCR serogroup identification using GLT and ORF2110 specific primers.

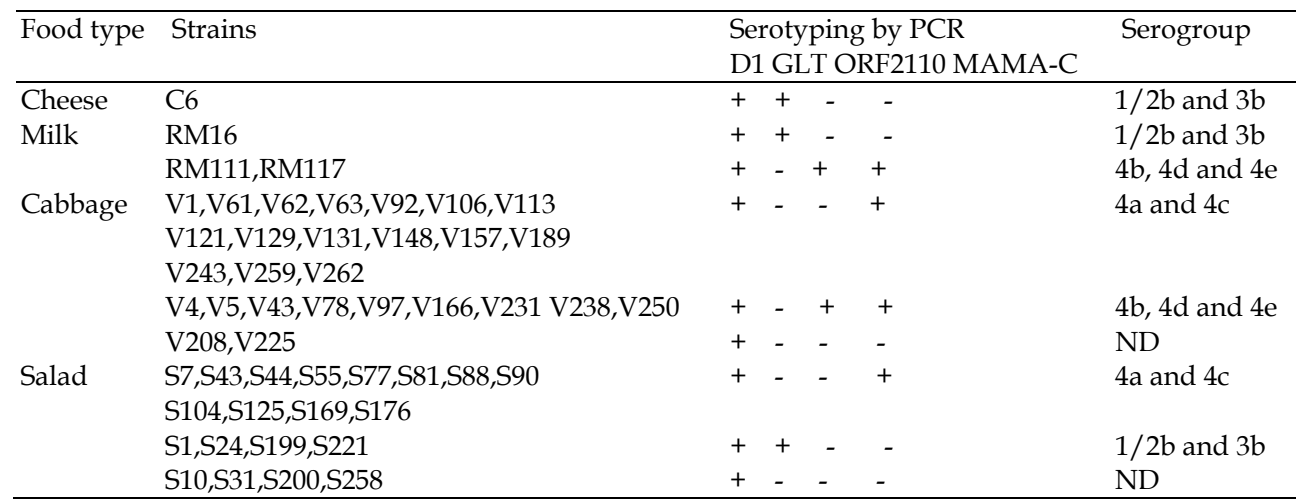

+ (positive), - (negative), ND (Not Determined)

Table 1. Serotyping of L. monocytogenes by PCR.

\subsection{Typing by repetitive element sequence based PCR}

From the 57 L. monocytogenes strains that were isolated, 41 were selected and typed using REP-PCR. DNA fingerprints obtained for all isolates had a maximum of five bands ranging from $200 \mathrm{bp}$ to $300 \mathrm{bp}$ (See figure 5. A, B, C and D). The DNA fingerprints were analyzed using a cluster analysis computer program to derive a dendrogram. A total of 5 clusters could be clearly distinguished at similarity level of more than $40 \%$ (Fig. 6) which are designated I, II, III, IV and V. The REP-PCR profiles of the isolates seemed to cluster according to food types, with most of the isolates from salad and cabbage falling into group I and V respectively. The three L. monocytogenes isolated from milk fell into group II while all five cheese isolates selected for REP-PCR analysis fell into group III. Group IV was heterogenous group with a balanced mixture of isolates from salad and cabbages. Two pairs of isolates from the two food types had identical REP-PCR profiles (S7 was similar to V131, 
while S10 was similar to V157). Cabbage had the most diverse REP-PCR profile types that appeared in 4 of the 5 REP-PCR profile groups. Only REP-PCR profile group I had isolates from one commodity (salads). There was no correlation between the REP-PCR clusters and serogroup or the three L. monocytogenes genetic lineages.
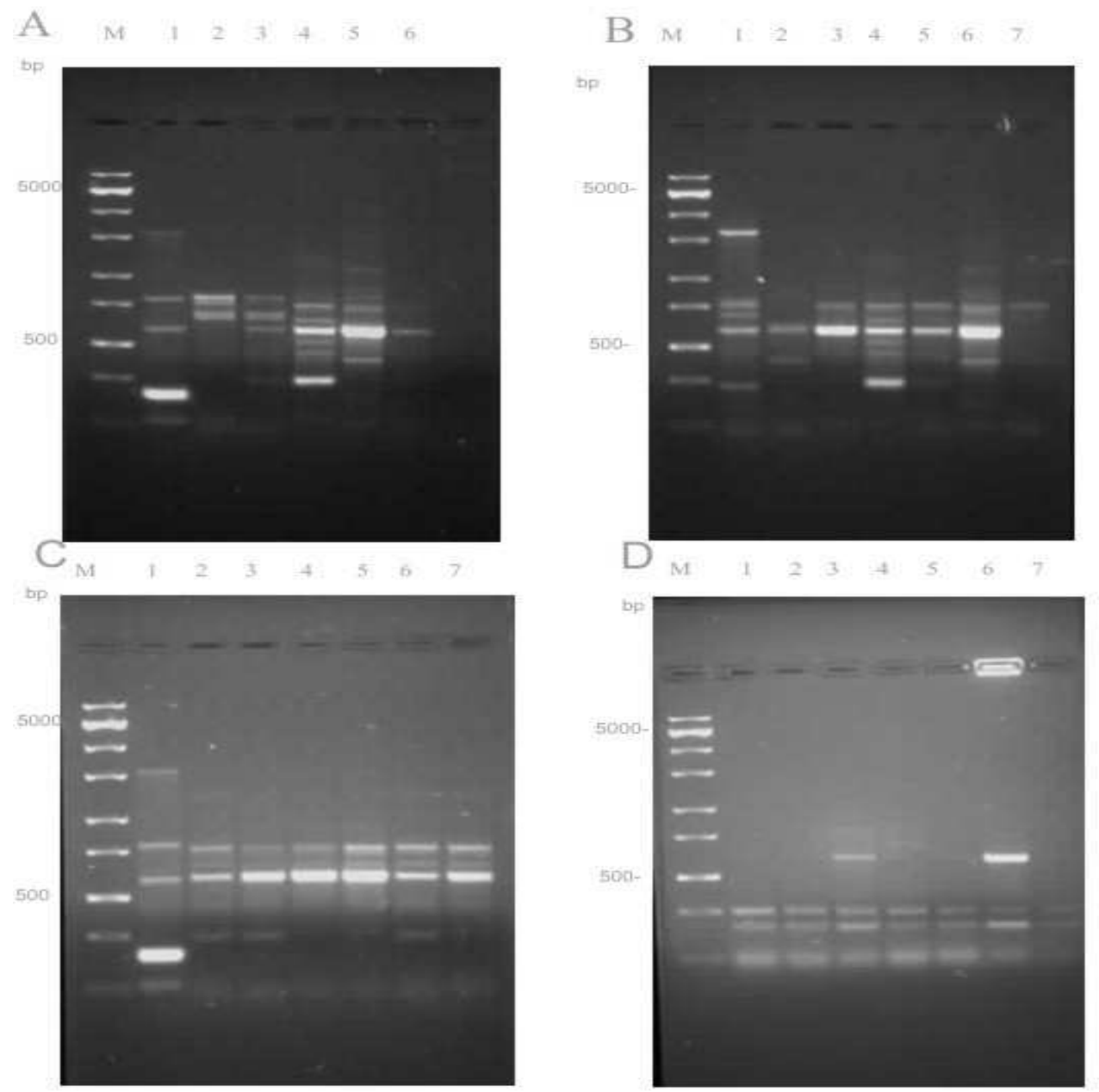

Fig. 5. REP - PCR fingerprints of Listeria monocytogenes isolates (lane 1-7). Lane M, ZipRuler TM SM1378 (Fermentas). A and B shows the diverse profiles of isolates obtained from cabbage and salads. $C$ and D shows isolates with similar REP-PCR profiles obtained from cabbage and salads respectively. 
Dice (Opt 1.00\%) (Tol 1.0\%-1.0\%) $(H>0.0 \% \mathrm{~S}>0.0 \%)[0.0 \%-100.0 \%]$

REP

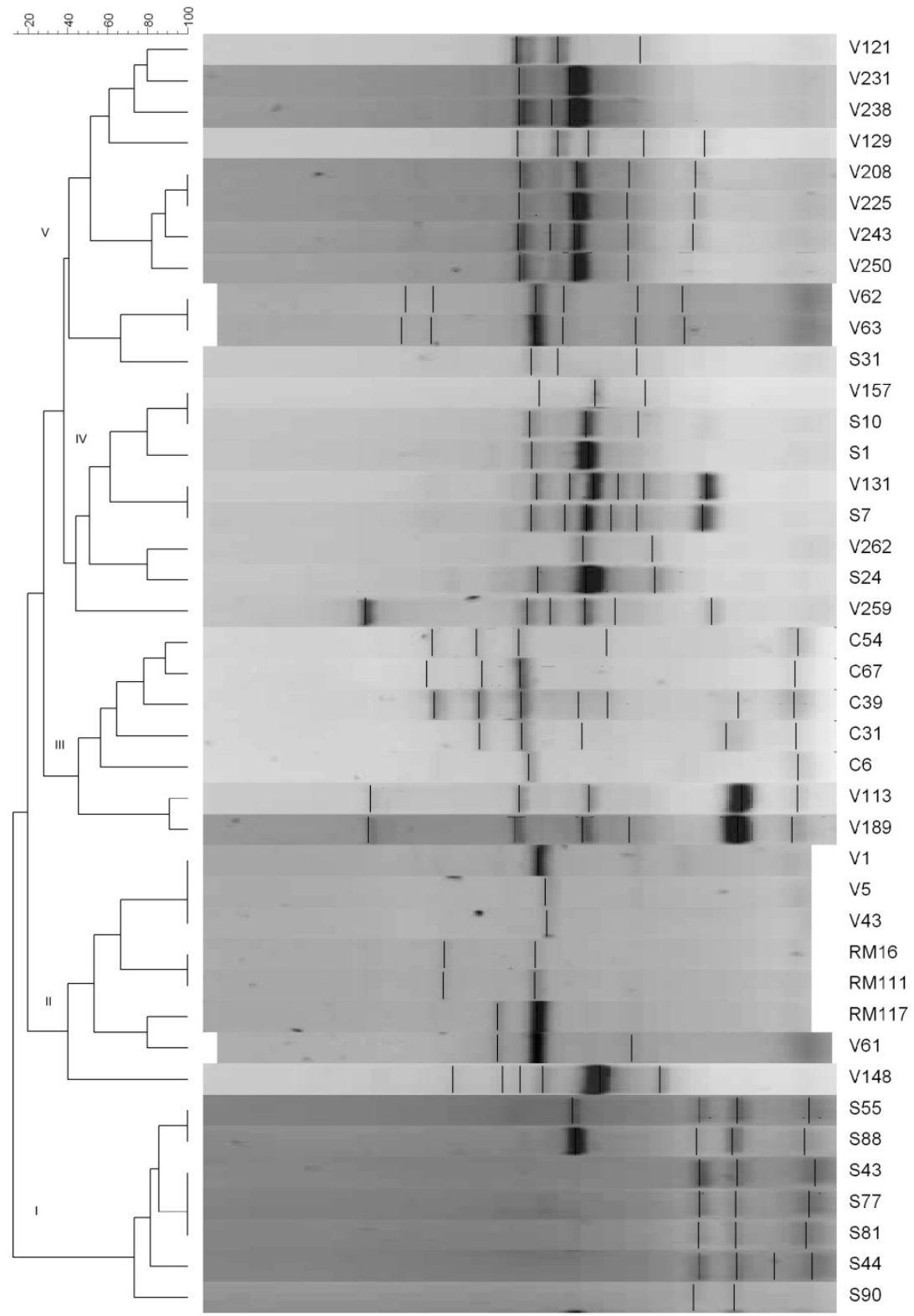

Fig. 6. REP-PCR Dendrogram representing similarity between L. monocytogenes isolates. 


\section{Discussion}

In this study serogrouping by PCR suggests serotypes belonging to phylogenetic lineage of division I and III, which comprise serogroups 1/2b, 3b, 4a, 4b, 4c, 4d and 4e. Isolates within this group appeared in all food types except salads. It was found that isolates with $1 / 2 b$, and $3 \mathrm{~b}$ were rare with only four isolates appearing in salad and one isolate being picked up in cheese and milk respectively. This is in contrast to most studies that have found serotypes $1 / 2 \mathrm{a}$ and $1 / 2 \mathrm{~b}$ were to be the most common serotypes in food (Aarnisalo et al., 2003), a finding also supported by Gilot et al., (1996) in a study of foods in Belgium. A study by Wallace et al., (2003) also found serovar 1/2a in $90 \%$ of all the Listeria monocytogenes isolates tested in food samples. The results obtained from the current study indicated a correlation between certain serotypes and specific food products, serogroups $1 / 2 b$ and $3 b$ was absent from Cabbage, a food type that had more L. monocytogenes isolates than other food type. This observation is in line with results obtained by Vitas and Garcia-Jalon (2004) in a study of fresh and processed foods in Navarra, Spain. In the present study serogroup $4 \mathrm{~b}, 4 \mathrm{~d}$ and $4 \mathrm{e}$ was present in $30 \%$ isolates retrieved from the food. This is significant because among the Listeria monocytogenes serotypes, serotype $4 \mathrm{~b}$ has been the number one serotype associated with human listeriosis (Zhang et al., 2007).

One major finding in this study is that the majority of the isolates found in food samples belonged to lineage III $(4 \mathrm{a}, 4 \mathrm{c})$, which is contrary to results found in previous studies (Gray et al., 2004; Ward et al., 2004). Isolates in lineage III are known to be more prevalent in animals with clinical Listeriosis (Jeffers et al., 2001). What was also significant was that isolates belonging to division II were not detected; no isolates were positive for PCR using D2 specific primers. Division two has serovar $1 / 2 \mathrm{a}$, a serotype common in food products. Furthermore, four samples belonged to division I, namely; S10, S31, S200 and S258 from salads, V208 and V225 from cabbage, but could not be characterized further into serogroups because they proved to be negative for PCR serogroup identification using GLT and ORF2110 specific primers. This proved to be one of the major limitation of serotype identification by PCR, in that some isolates could not be conclusively be allocated to serogroups. One other shortcoming of serotyping by PCR is that isolates could not definitively be allocated to specific serotypes but only indicated a number of possible serogroups or a division. However, these results are not surprising as the PCR assays used were not based on genes encoding serotype-specific antigens.

Using REP-PCR Typing a significant observation in the results was that most diverse isolates in this study were more common in cabbage and salads than the dairy products. This was to be expected as relatively few Listeria isolates were isolated from dairy products. Variations within the sizes of PCR generated fragments using REP-PCR was observed with this studies and two studies carried out by Wojciech et al., (2004). The amplicons obtained by Wojciech et al., (2004) were shorter with sizes ranging between 123 to $735 \mathrm{bp}$, in comparison to amplicons obtained by Jersek et al., (1998) with sizes ranging from 298 to $6100 \mathrm{bp}$. In this study amplicons obtained ranged from $200 \mathrm{bp}$ to $3000 \mathrm{bp}$. Though the same primers were used, the reason of such differences could be the variation in the DNA polymerase used, PCR machines and protocols used in this study.

In this study, REP-PCR was used as a tool to characterize L. monocytogenes strains isolated from food. This method showed great possibilities for the typing of L. monocytogenes, as 
isolated strains showed very similar REP-PCR fingerprints by visual comparison and cluster analysis but managed to show diversity between strains. These data supports previous studies that suggest that REP-PCR can be used as an alternative method for typing $L$. monocytogenes such as automated ribotyping which has proven to be a valuable epidemiological tool in investigations of many infectious diseases.

\subsection{Conclusion}

The findings clearly highlight the possible occurrence of L. monocytogenes $1 / 2 \mathrm{~b}$ and $4 \mathrm{~b}$ among foods served by retailers and street vendors in Gaborone. The presence of this human pathogen in ready-to-eat foods should be considered as having significant public health implications, particularly among the immuno-compromised and HIV/AIDS persons who are at greater risk. In order to solve the problems in this study, there is a need for close co-operation between the products suppliers, supermarket management, workers, especially cleaning agents, the staff of cleaning companies, and hygiene specialists from the food industry and health inspectors from the Ministry of health. Street vendors need to be educated about ill health imposed by consumption of food contaminated by $L$. monocytogenes, on the other hand retailers need to be trained and be vigilant of retail assistants on the importance of maintaining the cold chain in order to prevent food borne disease outbreaks. Considering the occurrence of power disruptions that occur now and then and the high ambient temperatures experienced, Supermarket managers should be encouraged to invest in stand-by generators to serve during periods when power cuts occur.

\section{Acknowledgements}

The authors wish to convey sincere gratitude and thanks to the University of Botswana, University of South Africa, Walter Sisulu University and National Research Foundation (NRF) South Africa, for providing financial assistance for this research work. We are indebted to Mr Daniel Loeto for the great technical assistance provided during this work. Special thanks go to Dr M. Ditlhogo, Ex-Head of Biological Sciences Department and all the microbiology staff for their unique roles. Finally, appreciation is extended to supermarket managers and street vendors for affording us the opportunity to collect the various samples.

\section{References}

Aguado, V., Vitas, A. I. and Garcia-Jalon, I. 2004. Characterization of Listeria monocytogenes and Listeria innocua from vegetable processing plant by RAPD and ERA. Internationasl Journal of Food Micrbiology 90: 341-347.

Bille, J., Catinel, B., Bannerman, E., Jacquet, C., Yersin, M.N., Caniaux, I., Monget, D. and Rocourt, J. 1992. API Listeria, a new and promising one-day system to identify Listeria isolates. Journal of Applied and Environmental Microbiology 58: 1857-1860.

Baloga, C., Bernande, C., Passone, N., Minssart, P., Kamalo, C., Mbolidi, D. and Germani, Y. 2006. Primary and opportunistic pathogens associated with meningitis in adults in Benguin, Central African Republic. In relation to human immunodeficiency virus serostatus. International Journal ofInfectious Diseases 10: 387-395.

Boruki, M. K. and Call, D. R., 2003. Listeria monocytogenes Serotype Identification by PCR. Journal of Clinical Microbiology, Vol. 41, No. 12 (December 2003), pp. (5537-5540), ISBN: 0095-1137. 
Buchanan, R.L, Smith, J.L, and Long W. 2000. Microbial risk assessment: dose-response relations and risk characterization. International Journal of Food Microbiology, Vol. 58, No. 2000 (November 2000), pp. (159-172), ISBN: PIIS0168-1605(00)00270-1.

Charpentier, E., and Courvalin, P., 1999. Antibiotic resistance in Listeria species. American Society for Microbiology, Vol. 43, No. 1 (July 1995), pp. 2103-2108, ISBN: 0022-1800.

Charpentier, E., Gerbaud, G., Jacquet, C., Rocourt, J. and Courvalin, P. 1995. Incidence of antibiotic resistance in Listeria species. Journal of Infectious Diseases 172: 277-281.

Chen, Y. and Knabel, S. J., 2007. Multiplex PCR for simultaneous detection of bacteria of the genus Listeria, Listeria monocytogenes and Major serotypes and epidemic clones of $L$. monocytogenes. Applied and Environmental Microbiology, Vol. 73, No. 19 (August 2007), pp. 6299-6304, ISBN: 0099-2240.

Chintu C., Bathirunathan N., 1975. Bacterial meningitis in infancy and childhood in Lusaka ( One year prospective study). Medical Journal of Zambia.9:150-7

Chopra I.,and Roberts M. 2001. Tetracycline Antibiotics: Mode of action, Application, Molecular Biology, and Epidemiology of Bacterial Resistance. MMBR 65: 232-260.

Doumith, M., Buchrieser, C., Glaser, P., Jacquet, C., and Martin, P., 2004. Differentiation of major Listeria monocytogenes serovars by multiplex PCR. Journal of Clinical Microbiology, Vol.42 No.8 (August 2004), pp. (3819-38220), SBN 0095-1137.

Duffy, L.L., Vanderlinde, P.B., and Grau, F.H. 1994. Growth of Listeria monocytogenes on vacuum-packed cooked meats; effects of low $\mathrm{pH}$, aw, nitrite and ascorbate. International Journal of Food Microbiology, Vol. 23, issues 3-4 (November 1994), pp. (377-390), ISSN:1517-8382.

Farber, J. M, and Peterkin, P.I., 1991. Listeria monocytogenes: a food-borne pathogen. Microbiology Review, Vol. 55, No. 4 (September 1991), pp. (476-511), ISBN: 04448814981.

Gilot, P., Genicot, A., and Andre, P. 1996. Serotyping and esterase typing for analysis of Listeria monocytogenes populations recovered from foodstuffs and from human patients with listeriosis in Belgium. Journal of Clinical Microbiology 34: 1007-1010.

Gray, M. J., Zadoks, R. N., Fortes, E. D. and 7 other authors (2004). Listeria monocytogenes isolates from foods and humans form distinct but overlapping populations. Applied and Environmental Microbiology 70, 5833-5841.

Hohne K., LooseB., Seeliger H.P.,1975. Isolation of Listeria monocytogenes in slaughter animals and bats of Togo (West Africa).Annual Microbiology (Paris).126A:501-7.

Leimeister-Wachter M. , and Chakraborty T . 1989. Detection of Listeriolysin, the Thiol Dependent Hemolysin in Listeria monocytogenes, Listeria ivanovii, and Listeria seeligeri . America Society for Microbiology 57: 2350-2357.

Huss, H.H., Jorgenssen, L.V., and Vogel, B.F. 2000. Control options for Listeria monocytogenes in seafood. International Journal of Food Microbiology, Vol. 62, No. 1 (November 2000), pp. (267-274), ISBN:0021-9193.

Jacquet, C., Gouin, E., Jeannel, D., Cossart, P. and Rocourt. J., 2002. Expression of ActA, Ami, $\mathrm{InlB}$, and listeriolysin $\mathrm{O}$ in Listeria monocytogenes of human and food origin. Applied Environmental Microbiology, Vol. 68, No. 1 (November 2002), pp. (616-622).

Jeffers, G. T., Bruce, J. L., McDonough, P. L., Scarlett, J., Boor, K. J. and Wiedmann, M. (2001). Comparative genetic characterization of Listeria monocytogenes isolates from human and animal listeriosis cases. Microbiology 147, 1095-1104. 
Jersek B. P., Gilot M., Klun N. and Mehla J., 1999. Typing of Listeria monocytogenes strains based on repetitive element sequences-based PCR. Journal of Clinical Microbiology. 37:103-109.

Kathariou, S. 2000. Pathogenesis determinants of Listeria monocytogenes, p. 295-314. In J.W. Cary, J.E. Linz and D. Bhatnagar (ed.), Microbial foodborne diseases. Technomics Publishing Co., Inc., Lactaster, PA.

Kunene, N.F., J.W. Hastings and A. Von Holy, 1999. Bacterial populations associated with a sorghum based fermented weaning cereal. International Journal of Food Microbiology 49(1-2): 75-83.

Kurunasagar, I., Krohne, G. and Goebel W., 1993. Listeria ivanovii is capable of cell-to-cell spread involving Actin Polymerization. Journal of Infection and Immunity, Vol. 61, No.1 (October 1993), pp. (162-169), ISBN: 0019-9567.

Manani, T. A., Collison, E. K., Mpuchane, S. 2006. Microflora of minimally processed frozen vegetables sold in Botswana. Journal of Food Protection, Vol. 69, No. 11 (November 2006), pp. (2581 - 2586), ISBN: 17133799 Pubmed.

McLauchlin, J., Mitchel, R.T., Smerdon, W.J., and Jewell, K., 2004. Listeria monocytogenes and listeriosis. A review of hazard characterization for use in microbial risk assessment of foods. International Journal of Food Microbiology, Vol. 92, No. 3 (October 2004), pp. (15-33), ISBN: 0387890254.

Mead, P.S., Slutsker, L., Dietz, V., McCraig, L.F., Breese, J.S., Shapiro, C., Griffin, P.M., and Tauxe, R.V., 1999. Food-related illness and death in the United States. Emerging Infectious Diseases, Vol. 5, No.5 (October 1999), pp. (607-62), ISBN: 10511517 Pubmed.

Mosupye F. M. and Von Holy A. 2000. Microbiological hazard identification and exposure assessment of street food vending in Johannesburg, South Africa. International Journal of Food Microbiology 61:137-145.

Njagi L.W., Mbathia P.G., Bebora L.C., Nyaga P.N., Minga U., Olsen J. E., 2004. Carrier status for Listeria monocytogenes and other Listeria species in free range farm and market healthy indigenous chicken and ducks.East African Medical Journal.81:529-33

Pitcher, D.G., Saunders, N.A. and Owen R.J., 1989. Rapid extraction of bacterial genomic DNA with guanidium thiocyanate. Letters in Applied Microbiology, Vol. 8, No. 1 (January 1989), pp. (151-156), ISBN: 1472765X.

Poyart-Salmeron, C., Trieu-Cuot, P., Carlier, C., MacGowan, A., McLauchlin J., and Courvalin, P. 1992. Genetic basis of tetracycline resistance in clinical isolates of Listeria monocytogenes, Antimicrobial Agents and Chemotherapy 36: 463-466.

Rodriguez-Lazaro, D., Hernandez, M., Scortti, M., Esteve, T., Vazquez-Boland, J.A. and Pla, M. 2004. Quantitative detection of Listeria monocytogenes and Listeria innocua by Real-Time PCR: Assessment of hly, iap and lin 02483 targets and Amplifluor technology. Journal of Applied and Environmental Microbiology 70: 1366-1377.

Rodriguez, L., and Cepeda Saez, A. 1994. Susceptibilities of Listeria species isolated from food to nine antimicrobial agents, Antimicrobial Agents and Chemotherapy, Vol. 38, No. 7 (July 1994), pp. (1655-1657), ISBN:0066-4804.

Seeliger, H.P. and Hohne, K. 1979. Serotyping of Listeria monocytogenes and related species. Methods in Microbiology 13: 31-49.

Wallace, F.M., Call, JE., Porto, A.C.S., Cocoma, G.J., ERRC Special Projects Team, and Luchansky., J.B. 2003. Recovery rate of Listeria monocytogenes from commercially 
prepared frankfurters during extended refrigerated storage. Journal of Food Protection, Vol. 66, No.1 (December 2003), pp. (584-591), ISBN:0781793947.

Ward, T. J., Gorski, L., Borucki, M. K., Mandrell, R. E., Hutchins, J. and Pupedis, K. (2004). Intraspecific phylogeny and lineage group identification based on the prfA virulence gene cluster of Listeria monocytogenes. Journal of Bacteriology 186, 49945002.

Wiedmann, M., Barany, F., and Batt, C.A., 1993. Detection of Listeria monocytogenes with a Nonisotopic Polymerase Chain Reaction-Coupled Ligase Chain Reaction Assay. Applied Enviromental Microbiology, Vol. 59, No.8 ( August 2003), pp. (2743-2745), ISBN:0099-2240.

Wojciech, L., Kowalczyk, K., Staroniewicz, Z., Kosek, K., Molenda, J., and Ugorski, M. 2004.Genotypic characterization of Listeria monocytogenes from foodstuffs and farm animals in Poland. Journal of Bacteriology, Vol. 186, No.14 (July 2004), pp. (427-435), ISBN:1740-8261.

Wong, A.C. 1998. Biofilms in food processing environment. Journal of Dairy Science 81: 27652770.

Wouters, P. C., Dutreux, N., Smelt, J. P. P., and Lelieveld, H. L. M., 1999. Effects of Pulse Electric Fields on Inactivation Kinetics of Listeria innocua. Applied and Enviromental Microbiology, VOL. 65, No. 12 (September 1999), pp. (5364-5371), ISNB:0099-2240.

Yücel, N., Citak, S. and Önder, M., 2005. Prevalence and resistance of Listeria species in meat products in Ankara, Turkey. Food Microbiology, Vol. 22, No. 2005 (March 2005), pp. (241-245), ISBN:0740-0020.

Zang, W. and Knabel, S.J. 2005. Multiplex PCR assay simplifies serotyping and sequence typing of Listeria monocytogenes associated with human outbreaks. Journal of Food Protection 68: 1907-1910.

Zhang, Y., Yeh, E., Hall, G., Cripe, J., Bhagwat, A.A. 2007. Characterization of Listeria monocytogenes isolated from retail foods. International Journal of Food Microbiology, Vol. 113, No. 2007 (July 2006), pp. ( 47-53), ISBN:1845938801. 


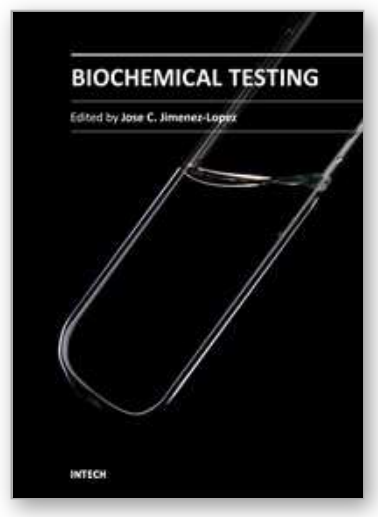

\author{
Biochemical Testing \\ Edited by Dr. Jose C. Jimenez-Lopez
}

ISBN 978-953-51-0249-6

Hard cover, 216 pages

Publisher InTech

Published online 07, March, 2012

Published in print edition March, 2012

Biochemical testing necessitates the determination of different parameters, and the identification of the main biological chemical compounds, by using molecular and biochemical tools. The purpose of this book is to introduce a variety of methods and tools to isolate and identify unknown bacteria through biochemical and molecular differences, based on characteristic gene sequences. Furthermore, molecular tools involving DNA sequencing, and biochemical tools based in enzymatic reactions and proteins reactivity, will serve to identify genetically modified organisms in agriculture, as well as for food preservation and healthcare, and improvement through natural products utilization, vaccination and prophylactic treatments, and drugs testing in medical trials.

\title{
How to reference
}

In order to correctly reference this scholarly work, feel free to copy and paste the following:

I.C. Morobe, C.L. Obi, M.A. Nyila, M.I. Matsheka and B.A. Gashe (2012). Molecular Characterization and Serotyping of Listeria monocytogenes with a Focus on Food Safety and Disease Prevention, Biochemical Testing, Dr. Jose C. Jimenez-Lopez (Ed.), ISBN: 978-953-51-0249-6, InTech, Available from: http://www.intechopen.com/books/biochemical-testing/molecular-characterization-and-serotyping-of-listeriamonocytogenes-isolates-from-various-foods-in-g

\section{INTECH}

open science | open minds

\author{
InTech Europe \\ University Campus STeP Ri \\ Slavka Krautzeka 83/A \\ 51000 Rijeka, Croatia \\ Phone: +385 (51) 770447 \\ Fax: +385 (51) 686166 \\ www.intechopen.com
}

\author{
InTech China \\ Unit 405, Office Block, Hotel Equatorial Shanghai \\ No.65, Yan An Road (West), Shanghai, 200040, China \\ 中国上海市延安西路65号上海国际贵都大饭店办公楼405单元 \\ Phone: +86-21-62489820 \\ Fax: +86-21-62489821
}


(C) 2012 The Author(s). Licensee IntechOpen. This is an open access article distributed under the terms of the Creative Commons Attribution 3.0 License, which permits unrestricted use, distribution, and reproduction in any medium, provided the original work is properly cited. 